Revista de la red interuniversitaria de estudios sobre las literaturas rioplatenses contemporáneas en Francia

17 | 2017

Hermetismo programático en la literatura rioplatense contemporánea (de 1980 a nuestros días)

\title{
Lo ilegible, el cuerpo
}

\section{Jean-Marc Talpin}

Université de Nantes (ed.)

Translator. Sonia Fernández Hoyos

\section{(2) OpenEdition}

\section{Journals}

\section{Electronic version}

URL: http://journals.openedition.org/lirico/3963

DOI: $10.4000 /$ lirico.3963

ISSN: 2262-8339

\section{Publisher}

Réseau interuniversitaire d'étude des littératures contemporaines du Río de la Plata

\section{Electronic reference}

Jean-Marc Talpin, « Lo ilegible, el cuerpo », Cuadernos LIRICO [En línea], 17 | 2017, Puesto en línea el 17 diciembre 2017, consultado el 20 abril 2019. URL : http://journals.openedition.org/lirico/3963 ; DOI : 10.4000/lirico.3963

This text was automatically generated on 20 April 2019

\section{(c) (i) (3) $\Theta$}

Cuadernos LIRICO está distribuido bajo una Licencia Creative Commons Atribución-NoComercialSinDerivar 4.0 Internacional. 


\title{
Lo ilegible, el cuerpo
}

\author{
Jean-Marc Talpin \\ Université de Nantes (ed.) \\ Translation : Sonia Fernández Hoyos
}

\section{EDITOR'S NOTE}

En nombre de Cuadernos LIRICO agradecemos el acuerdo del autor para publicar esta traducción. El original en francés fue publicado en La lecture littéraire, $n^{\circ} 3$ (URCA, Reims, 1999), p. 195-204. Las notas de traducción se incluyen entre corchetes.

1 Cuántas veces me dijeron, de niño: «tu escritura es ilegible ». Creo que entonces solo lo tomaba como una observación sobre mi caligrafía. Pero al emprender una tesis en psicología de la lectura, hace ya algunos años, y más tarde, al preparar este texto, la pregunta volvió a surgir: ¿lo ilegible era mi escritura o yo mismo?

2 En mi torpeza, me fusionaba, y sigo fusionándome, con mi escritura. Mi escritura se fundía con mi cuerpo, ofreciendo a los demás el escudo de esos signos herméticos que encontraba elegantes; sin duda había en ellos un deseo de secreto, de impenetrabilidad.

3 Ya entonces, pues, lo legible remitía al cuerpo. Sin embargo, hablaré aquí de otro aspecto de lo ilegible, del que está ligado no a la grafía sino al estilo, a la construcción del texto literario.

\section{Introducción}

4 Lo ilegible es a menudo pensado, en los trabajos que lo abordan (tal como lo demuestra de manera precisa un número de 1993 de la revista Quai Voltaire), dentro de la lógica, enunciada ya por S. Mallarmé, de la distancia entre la palabra y la cosa, entre el cuerpo y el lenguaje, incluso dentro de una lógica metafísica del lenguaje. El trabajo de R. Chambers sobre la lectura de textos difíciles va en este sentido también, al plantear la cuestión de lo ilegible a la luz del concepto de interpretación, entendida esta última como lo que permite salir de una lectura «mecánica» al manifestar la irreductible 
heterogeneidad del lector y de su texto: todo texto, en suma, sería difícil, lo cual cuestiona entonces su legibilidad, sin que por ello llegue necesariamente hasta lo ilegible, en la medida en que el sentido no es nunca inmediato.

5 Hayan sido concebidos o no como tales, numerosos textos del siglo xx son percibidos por los lectores como ilegibles. La elección de trabajar sobre literaturas contemporáneas permite distanciarse de los problemas de ilegibilidad ocasionados por la pérdida de códigos, de sistemas de referencias que funcionan como sistemas simbólicos; pero al mismo tiempo permite tomar en consideración estilos muy diferentes, de Proust a Guyotat pasando por Joyce, Beckett o Sollers.

6 La hipótesis aquí desarrollada para mostrar este efecto de ilegibilidad estilística, y no escritural, en el sentido de la grafía -aunque la cuestión puede plantearse a propósito de obras tales como Le livre, de P. Guyotat-, es la siguiente: el texto ilegible violenta al lector y esa violencia se transmite en la experiencia psíquica y física de la lectura. Se tratará la cuestión del cuerpo metafórico del texto y el cuerpo físico del lector, en particular en lo que respecta a la respiración, al ritmo y a la voz, manteniendo en suspenso por razones metodológicas y temáticas, la cuestión del cuerpo del autor. En efecto, la lectura en voz alta o baja, en todo caso la lectura sonorizada (volveré a ello), es utilizada por ciertos lectores y por ciertos autores para superar este efecto de ilegibilidad: se analizará esta vuelta y este recurso al cuerpo para comprender mejor lo que se juega en y por lo ilegible.

7 Mi objetivo deberá ser, en parte, entendido como una respuesta a P. Bergougnioux y su hermoso texto Haute tension; para él:

«La ilegibilidad procede de la dualidad de nuestra condición. Estamos sujetos a un cuerpo finito, efímero, espontáneamente proclive a ignorarnos y privados, sin embargo, del sentido de nuestras vidas. Pero también estamos (igualmente) provistos de conciencia, somos capaces de representaciones que exceden los límites de nuestra situación ».

Mientras que para P. Bergougnioux la heterogeneidad cuerpo / conciencia es la causa infranqueable, salvo en la tensión de la poesía, de lo ilegible, considero por mi parte que, en relación con ciertos textos experimentados como ilegibles, recurrir al propio cuerpo permite, al contrario, restablecer, a través de la voz y por lo tanto de la respiración rítmica, un vínculo entre el texto y el lector, y, en este último, entre cuerpo y psique (más que con la conciencia). En efecto, lo ilegible no concierne ni al texto solo ni al lector solo, sino más bien a la relación del uno con el otro, a sus vínculos, sus modos de relacionarse. Es decir, el recurso a la voz no es sino una respuesta universal a lo ilegible: corresponde a un intento específico del lector, que depende sin duda en parte de la lógica del texto; es cierto que existen otras numerosas causas de la experiencia de la ilegibilidad que el recurso a la voz no aclara.

\section{Puntos de referencia}

\section{El cuerpo en la lectura}

9 En nuestra cultura, la lectura de textos literarios hecha por adultos no solo es silenciosa sino también, por lo general, muda. Además, se acompaña de una inhibición motriz y de una relativa pérdida de los sentidos excepto el de la vista. Es decir que el cuerpo está por lo menos puesto en sordina, puesto en suspenso mientras dura la captación del lector por el texto; es decir también que toda manifestación del cuerpo, todo regreso del cuerpo en 
la lectura, ya sea voluntario o inconsciente, puede leerse como un síntoma de la combinación texto-lector, combinación que es entonces puesta en dificultad y comporta el riesgo de provocar la desconexión en cadena de las relaciones y de los vínculos inter e intra psíquicos.

10 A modo de ilustración, evocaré aquí lo que atañe al cuerpo cuando se leen textos eróticos: el texto erótico vuelve el cuerpo del lector visible al inscribirlo simultáneamente en sus dimensiones biológicas y funcionales; por añadidura, a causa de la excitación sexual, la remite a su propio ritmo, que puede ser eventualmente masturbatorio. Algo parecido ocurre cuando se leen textos de terror o de suspense: el cuerpo participa en la experiencia y en la expresión de las emociones en el plano de los ritmos respiratorios, cardíacos, en el plano de la temperatura interna...

11 Veremos que, por otras razones, que no excluyen ciertamente la dimensión del afecto, los textos experimentados como ilegibles pueden también solicitar el cuerpo dentro de una perspectiva que asocia una pragmática y una metapsicología de la lectura.

\section{Lo legible, ¿una ilusión?}

12 ¿En qué se basa la impresión de legibilidad de un texto para el lector? Pueden inferirse dos lógicas para responder a esta pregunta. En la primera, hay una actitud de desprecio del lector con respecto al texto: lo cree tan legible que, en cierto modo, prescinde de él o lo simplifica en función de sus propias expectativas al hacer desaparecer fragmentos enteros de sentido. Dentro de la segunda lógica, que es para mí la que rige la verdadera lectura de los textos literarios, lo legible, la legibilidad, se elaboran apoyándose en una mecánica psíquica compleja entre el dispositivo psíquico preestablecido del texto y el psiquismo del lector tal como cada texto particular lo trabaja. He propuesto que esta lectura se basa en un pacto entre el texto y el lector. Dicho pacto comporta un aspecto positivo (el reparto de representaciones y de significantes articulados según los ritmos y las construcciones originales) y un aspecto negativo (cfr. lo que R. Kaës designa como pacto denegativo o pacto sobre lo negativo). Este segundo aspecto, que vincula sin duda el lector al texto de forma más profunda, trata sobre lo que ignorarán juntos; la negación tiene, entonces, por objeto los significantes, el cuerpo más acá de los significantes, en sus ritmos que remiten a experiencias arcaicas. El pacto reposa, pues, sobre el desprecio de creer el texto legible, pero recupera la heterogeneidad de partida, inherente a la lectura, creando una obturación, una negación de esta heterogeneidad.

\section{Recurso al cuerpo, regreso del cuerpo}

13 Si la lectura concierne en efecto, de cerca o de lejos, tres cuerpos, estos no tienen claramente el mismo estatus: el del autor está ausente, incluso si es posible encontrar marcas en el estilo del texto; el del texto no es más que cuerpo de imprenta o de metáfora; sólo el del lector está empíricamente presente y es requerido, aunque a costa de una relativa puesta en suspenso, y esto sin adentrarnos en el cuestionamiento del difícil problema de los cuerpos del lector (cuerpo empírico, imaginario, de deseo...).

14 Tal y como voy a desarrollarlo ahora con el fin de proponer una nueva perspectiva a mi hipótesis, el cuerpo está presente y es solicitado activamente en el origen de la lectura 
tanto en el plano de la historia de la humanidad como en el plano de la historia de cada sujeto.

\section{La invención histórica de la lectura muda} realizaba en voz alta. J. Svenbro lo demuestra perfectamente en su Phrasikléia. Articula en un primer momento la necesidad de la lectura en voz alta con la dificultad de leer un texto en scriptio continua: frente a este texto de un solo bloque, el lector debía crear blancos para el ritmo de su voz que, al separar las palabras, permitieran encontrarlas de nuevo y darle otra vez un sentido al texto. Además, en cuanto las palabras se separaron por puntos y luego por espacios en blanco, la escritura pudo enmudecer, interiorizarse, esto hacia el siglo IV a. C. Pero, en un segundo momento, J. Svenbro no se contenta con esta propuesta cognitiva: introduce las diferentes dimensiones simbólicas implicadas en la lectura, tanto en la lógica del renombre como en la de la filiación (y en la de Edipo, añadiría yo). En efecto, el escriba preveía que su texto sería leído en voz alta, haciéndolo resonar, dándole un « cuerpo sonoro »; dentro de esta práctica el lector desaparecía como sujeto para devenir portavoz y vocero del texto. La aparición de la lectura muda se corresponde entonces con una modificación política: la ley de la ciudad se interioriza en cada uno junto con la aparición de un espacio físico interno diferenciado del espacio público, del aparato psíquico externo, el de la ciudad. A partir de entonces la voz puede desaparecer, el texto « le habla al ojo en la lectura muda ». Sin embargo, el caso que nos ocupa aquí es aquel en el que precisamente el texto ha dejado de hablarle al ojo y en el que, habiendo enmudecido esa voz, el lector debe recurrir a lo sonoro.

16 En L'œil du silence M. Tasinato trabaja sobre la segunda aparición occidental de la lectura muda; San Ambrosio sería el actor, si seguimos a San Agustín. Esta segunda aparición de la lectura muda encuentra, como J. Svenbro, dimensiones cognitivas ligadas a la reaparición de la escritura continua, pero también dimensiones simbólicas que, esta vez dentro de la lógica cristiana, remiten la articulación de lo singular y de lo grupal.

\section{La invención singular de la lectura}

17 Cuando el niño aprende a leer, cuando inventa la lectura, hasta tal punto esta se encuentra dentro de él, profundamente, y tan integrada está en el propio método que le facilita el descubrimiento, que el niño empieza por leer en voz alta. Esto parece ser un pasaje obligado, incluso si, tal como apunta P. Saenger, la oralización es más o menos necesaria según la estructura de las lenguas y la de los códigos de escritura. Cuando el niño aprende a leer, pasa, pues, por una lectura en voz alta, en particular cuando se trata de descifrar palabras desconocidas, después por una lectura sonorizada, pero en la que la voz se hace baja, se interioriza incluso. El lector deja de recurrir a la oralización solo cuando se ha apropiado realmente de la lectura, excepto en circunstancias particulares como aquellas sobre las que trabajamos.

18 La oralización puede ser comprendida entonces como actividad cognitiva preliminar al reconocimiento de palabras. Volvemos a encontrar aquí los dos niveles de huellas mnémicas y de representación descritas por S. Freud: las huellas visuales, que constituyen las representaciones-cosas, y las huellas auditivas, que constituyen las representacionespalabras. Las representaciones-cosas son las primeras en la historia de la constitución del

Cuadernos LIRICO, 17 | 2017 
aparato psíquico y habitan en el inconsciente, mientras que las segundas aparecen más tardíamente y se inscriben en particular en el preconsciente. En la lectura, la cronología de la preeminencia de lo visual y de lo sonoro se invierte en la medida en que lo que se trata de ver no es ya la cosa, sino su representación gráfica abstracta y arbitraria, al mismo tiempo que altamente socializada. En el transcurso de un aprendizaje o de una simple dificultad de lectura, la palabra se convierte en una cosa no significante que restablece lo simbólico de ser, a partir de entonces, no sólo leída sino oída; la voz del lector, al introducir una distancia entre lo así dicho y lo así oído, convoca las voces lectoras que cada lector interioriza por identificación con el curso de su historia. Volveré a ello, la voz se añade como tercer vértice, quebrando entonces la dualidad entre el texto y el yo, entre la ilegibilidad, es decir también el no-sentido del texto que lo remite al ámbito de la cosa, y la tensión psíquicamente necesaria hacia la vinculación y, así, la simbolización, entre la grafía, la cosa, el sonido, el cuerpo y la psique.

\section{La experiencia corporal de leer}

Voy a asentar ahora estas exposiciones un poco abstractas y generales en algunas experiencias personales de lectura. Se trata de dos textos que me parecieron en un tiempo ilegibles, dificultad que me llevó a abandonarlos o a posponer su lectura. Estos textos no me parecían particularmente difíciles desde un punto de vista intelectual; su ilegibilidad se debía más bien a la opresión física que me provocaban. El primero de ellos es La Recherche du temps perdu, de M. Proust, el segundo, Cap au pire, de S. Beckett. Sin embargo, aunque podría haber sucedido lo mismo con otros textos del mismo autor, este último me parece particularmente revelador. Durante mucho tiempo no establecí ningún vínculo entre estas dos experiencias, al no utilizar tampoco el trabajo de Beckett sobre Proust. La conexión que posteriormente establecí se apoya, por una parte, en el hecho de que estos dos textos me planteaban problemas de ritmo y de respiración y, por otra parte, en la solución que encontré para poder abordar su lectura, lectura que pudo, después, proseguirse sin mayores dificultades. Tanto Proust como Beckett -no son ciertamente los únicos, pero esto depende de la sensibilidad específica de cada lector- imponen a sus lectores uno o dos ritmos muy marcados y que no son apropiables de inmediato. Paradójicamente, las largas frases de Proust y las breves, a veces muy breves frases, de Beckett producían en mí el mismo efecto: una opresión que, al situar mi cuerpo en el centro de mi experiencia de lectura, me impedía hallar, crear un sentido en aquello que leía. Encontramos de nuevo aquí los efectos que se unen de la hiperligazón [hyperliaison] (ciertas frases proustianas) y de la desligazón [déliaison] (las frases y a veces las no-frases beckettianas). La lectura sonorizada, más frecuentemente en voz baja, de ciertos pasajes de estos textos, me permitió tanto dejarme penetrar por ellos como penetrarlos, encontrar ritmos en los cuales tanto los ritmos de los textos, como los de mi cuerpo y los de mi pensamiento podían estar contenidos, encontrar una cierta coherencia sin que la tensión desapareciera del todo, no obstante.

\section{Lo ilegible en el juego de la voz}

Lo ilegible del texto y del pasaje por la voz plantean la cuestión no del acto de lectura (en el sentido desarrollado por W. Iser), sino del acto en la lectura, ya que este recurso a la voz sale del pacto y del marco de la lectura y, como mínimo, los transforma. En este 
punto, es necesario distinguir dos lógicas que pueden provocar la impresión de ilegibilidad de un texto en el lector.

21 La primera es neurótica: el texto encuentra al lector lo más cerca posible de un contenido reprimido; el efecto de sideración provocado por el encuentro con este contenido fuera de sí revela eso que S. Freud describió como « inquietante extrañeza ». De ello resulta una suspensión temporal de la posibilidad de recuperación a través de los procesos secundarios. El texto es, entonces, ilegible porque se lo lee demasiado bien. Estamos en el registro de una representación compartida, pero este compartir mismo provoca violencia.

La segunda se sitúa por debajo de la anterior y en ella me detendré. El lector ya no encuentra contenidos psíquicos reprimidos, sino algo que ha quedado en un estado de inscripción psíquica arcaica, algo que, rigurosamente hablando, no pertenece al ámbito de contenidos ni de representaciones, sino de lo experimentado, lo más cerca posible tanto de la sensorialidad externa como interna. En este caso, el lector no reacciona a los significantes, sino a la disposición rítmica de los mismos, que cuentan mucho menos dentro de la dimensión significante (sino de forma secundariamente defensiva) que dentro de la composición sensorial (visual, auditiva: $c f r$. por ejemplo el proyecto poético de S. Mallarmé). El ritmo del texto, que forja en buena medida su estilo, se inscribe lo más cerca posible de las experiencias corporales arcaicas del autor que las dispone proyectivamente dentro del texto y de aquellas del lector que es doblemente solicitado: por aquello que recibe del texto sobre el modo de la identificación proyectiva y por aquello que le incumbe a él mismo y se ve solicitado por la lectura de este texto. El texto parece, pues, ilegible porque solicita a través de sus ritmos las dimensiones prerepresentativas del psiquismo, lo que sin duda provoca angustia.

23 A partir de entonces, el recurso a la voz para superar la ilegibilidad del texto (lo que cuestiona el pacto de lectura que hace que el lector no pueda detenerse) remite a diferentes dimensiones que voy a desarrollar: la de la influencia y de su inversión, la del anclaje en la experiencia corporal propia y, por último, la de la convocación que sostiene la grupalidad interna.

\section{La influencia'}

En lugar de decir « percepción del ritmo », habría que hablar mejor de « ritmización de la percepción ", porque «la apropiación del ritmo-objeto en cuanto tal deviene posesión dentro del doble sentido de tenerlo y del serlo ", escribe N. Abraham. El texto vivido como ilegible maltrata, lo hemos visto a partir de algunas de mis experiencias de lectura, al lector y al cuerpo mismo; por ello, el lector experimenta una imposición rítmica que no puede apropiarse; es más bien él el que se siente apropiado por el texto, el que se siente víctima de la influencia que este ejerce sobre sí, incluso a su pesar, lo que moviliza tanto en lo real como en el fantasma este cuerpo habitualmente latente, tan poco presente, mientras dura la lectura. Dentro de una lógica que solo parece paradójica si no se desarrolla en la temporalidad de la inversión, el cuerpo es a la vez aquello que sufre la influencia del texto y aquello que, secundariamente pues, ejerce una influencia sobre él. Cuando el lector percibe la ilegibilidad del texto debida a la influencia rítmica de este sobre su cuerpo, el pacto de lectura vacila en virtud de una sensación de desposesión y de la irrupción del cuerpo hasta entonces en suspenso; el lector utiliza entonces este cuerpo convocado por el ritmo del texto dentro del registro de la voz, de la sonorización de este texto. Así, trabaja ya sea para volver la influencia contra el texto (le impone su propio 
ritmo, corriendo el riesgo de perder la emoción, el afecto en la lectura), ya sea para articular (pasando por la articulación fonadora) los ritmos textuales y sus ritmos psíquicos, testigos vivos de los ritmos de los intercambios con el objeto primario y las experiencias corporales precoces, conservadas como tales en el fondo del inconsciente y no simbolizadas, no representadas. La convocación del cuerpo del lector por el texto, por debajo, pues, del registro de sentido, se hace primero en el registro de un displacer. Pero, en la inversión antes mencionada, su movilización segunda en un movimiento de influencia eventualmente mutuo (lo que me parece el caso en toda lectura literaria, excepto cuando no sale bien), se inscribe dentro del restablecimiento del principio de placer al que obedece, por vías ciertamente desviadas, esta sublimación que es la lectura de textos literarios. El fracaso de esta inversión, parcial o total, de la influencia lleva a la conclusión de que el texto es ilegible y al detenimiento de su lectura.

\section{El anclaje corporal}

La lectura, realizada la mayoría de las veces en el silencio (que puede ser ruidoso) y en la casi inmovilidad corporal, puede volverse amenazadora en las condiciones ya expuestas. El recurso a la voz permite en ese momento salir de un silencio potenciador de la angustia experimentada, que desarrollaré más adelante en el punto siguiente, $\mathrm{y}$, además, reestablecer una conexión somato-psíquica de alguna manera palpable, perceptible. El lector vuelve a encontrar mediante su voz la materialidad sonora de las palabras: los significantes abstractos retoman "cuerpo sonoro" (J. Svenbro) en el apuntalamiento sobre el cuerpo del lector solicitado principalmente en su dimensión vocal, pero también gracias al trabajo de articulación y de desarticulación al que les ha sometido el autor. Sin embargo, estas articulaciones, estas conexiones no vuelven a salir de ellas mismas a través del lector en el estricto registro perceptivo de la vista: hay que añadir la actividad muscular de la fonación, con lo que comporta de percepciones internas, y la capacidad auditiva. El cuerpo del lector reencuentra entonces ahí un sosiego existencial, voluntariamente abandonado previamente, gracias al recurso a una poli-sensorialidad real y no ya metafórica, interiorizada y transpuesta al único registro de lo visto-leído.

\section{Voces narrativas, voces lectoras}

Si la lectura es, en efecto, un placer solitario, puede también convertirse en un displacer solitario en cuanto el texto que la sostiene es percibido y después representado como ilegible; en un movimiento circular, el displacer produce una experiencia vivida de ilegibilidad que a su vez genera displacer. La sonorización del texto por parte del lector permite salir de esta situación solitaria o, más bien, de este " estar a solas » con el texto. Al oírse leer, el lector puede apoyarse en una distancia figurable en relación consigo mismo entre aquel que lee y aquel que se oye leer. A partir de este momento, oye tanto el texto como a sí mismo, lo que puede ser una respuesta a la angustia generada por la influencia: siente que está vivo; no se ve reducido por el texto, al que es capaz de transformar volviéndolo más legible. Pero la voz lectora no puede ser reducida a la voz propia del lector, a menos que se considere que esta contiene la multiplicidad de voces que el sujeto ha interiorizado, con las que se ha identificado. Leer un texto en voz alta vuelve a convocar estas situaciones de la infancia en las que un tercero leía en voz alta; cuando leemos ino son siempre hasta cierto punto aquella madre, aquel padre, aquel hijo-hermano mayor quienes leen en nosotros, quienes leen para nosotros? Al hacer esto, 
muestran una capacidad de conexión y de simbolización que en un tiempo nos hizo falta de manera fundamental y que supieron prestarnos. Así, el desdoblamiento del lector entre voz lectora y posición de escucha, de recepción, no triangula solamente la situación, la reintroduce, ligada a la voz, a la grupalidad interna del lector. Se deriva de ello un punto importante que merecería profundizarse en relación con la literatura del siglo xx, que ha conducido a analizar de nuevo el modelo de la voz narrativa única. Antes de concluir, formularé, pues, la hipótesis de que lo que vuelve para muchos la literatura de nuestro siglo ilegible es que ella confronta al lector ya sea a la división de la voz narrativa que se hace poli-rítmica, y es necesario restituir en otro nivel una unidad, ya sea a su compacidad (pienso aquí en Bavard, de Louis-René des Forêts), figuras en las que encontramos de nuevo eso que evocaba al principio de este texto en términos de desligazón [déliaison] y de hiperligazón [hyperliaison]. La voz, anclada en lo corporal, pero que lleva una huella de lo psíquico arcaico y de lo simbólico, ofrece entonces al lector un espacio dinámico de legibilidad, porque ella es una y plural, ligazones [liaisons] y escansiones [scansions] lo son también.

Espero, al terminar estas palabras, haber podido escribir legiblemente sobre lo ilegible y no haber sido, por tanto, contaminado por el objeto, arduo, de esta investigación.

\section{BIBLIOGRAPHY}

Abraham, Nicolas. Rythmes de l'œuvre, de la traduction et de la psychanalyse. París: Flammarion, 1985. Beckett, Samuel. Cap au pire. París: Minuit, 1983.

Bergougnioux, Pierre. Haute tensión. Bordeaux: William Blake \& Co. 1996.

Chambers, Ross. «Le texte difficile et son lecteur ». Problèmes actuels de la lecture. Colloque de Cerisy, París: Clancier-Guénaud, 1983, p. 81-94.

Freud, Sigmund. Naissance de la psychanalyse appliquée. Paris: PUF, 1973.

Freud, Sigmund. «L'inquiétante étrangeté ». Essais de psychanalyse appliquée. París: Gallimard, , 1993, p. 163-210.

Green, André. La déliaison. Paris: Les belles lettres, 1992.

Iser, Wolfgang. L'acte de lecture. Théorie de l'effet esthétique. Liège-Bruxelles: P. Margade, 1976.

Kaës, René. «Le pacte dénégatif dans les ensembles transubjectifs ». Missenard, André et al. Le négatif, figures et modalités. París: Dunod, 1989, p. 101-136.

Quai Voltaire. Revue littéraire. L'illisibilité, n.. 7, invierno 1993.

Saenger, Paul. « Physiologie de la lecture et séparation des mots ». Annales, año 44, nº 4, 1989, p. 939-952.

Svenbro, Jesper. Phrasikléia. Anthropologie de la lecture en Grèce ancienne. París: La découverte, 1988.

Talpin, Jean-Marc. Pour une esthétique psychanalytique de la lecture du texte littéraire. Lire M. Duras. Thèse nouveau régime, Lyon, 1992. 
Talpin, Jean-Marc. « Lire: de l'entre-prise à l'inter-prèt ». La lecture littéraire, ㄲō1, L'interprétation. París: Klincksieck, 1996, p. 105-112.

Tasinato, María. L'œeil du silence. Eloge de la lectura. Lagrasse: Verdier, 1989.

\section{NOTES}

1. [El término utilizado en francés no es "influence " sino "emprise », un término que puede traducirse por « influencia », pero también por « control » o « dominio ».]

\section{AUTHORS}

JEAN-MARC TALPIN

Université Lumière Lyon 2 